\title{
Excavation of Lunar Regolith with Rippers for Improved Energy Efficiency
}

\author{
Masafumi $\mathrm{IAI}^{1,2)}$ and Leslie GerTsCH ${ }^{1)}$ \\ ${ }^{1)}$ Department of Geological Engineering, Missouri University of Science and Technology, MO, USA \\ ${ }^{2)}$ Axelspace Corporation, Tokyo, Japan
}

(Received June 21st, 2011)

\begin{abstract}
As humanity's activities expand to the Moon, Mars, and other extra-terrestrial bodies, it will be necessary to use local resources rather than bringing everything from the Earth. This concept is called In-Situ Resource Utilization (ISRU), which starts with excavation and earthmoving. The present study focuses on loosening and moving of the lunar regolith by a ripper (or rake) and a wide blade. After characterizing the lunar regolith and two of its simulants (JSC-1A), the relationship between the excavation energy and different conditions, namely, relative density- a ratio describing the density of a material with respect to its maximum and minimum density -, and tine spacing on a rake, is investigated with scaled experiments. Prior ripping decreases total excavation energy by up to $20 \%$ if the relative density is $>60 \%$. This study has proven that the characteristics of the lunar regolith, i.e. angular grains and high relative density, led to the effectiveness of ripping.
\end{abstract}

Key Words: $\quad$ Lunar Regolith, Ripper, ISRU, Excavation, Simulant

\section{Introduction}

\subsection{Background}

There has been continuous interest in permanent activity on the Moon since the Apollo missions ended. Researchers have been evaluating various technical concepts for industrialization and commercialization of the Earth-Moon system, such as lunar mining methods ${ }^{1)}$, concrete production from lunar regolith ${ }^{2)}$, lunar oxygen production ${ }^{3)}$, solar cell production on the Moon ${ }^{4}$, and the Lunar Ring concept, a large scale solar power generation ${ }^{5)}$. Following tens of lunar missions by the US and Soviet in the 20th century, the new millennium has begun with more attention to the Moon by the broad international community: European SMART-1 launched in 2003, Japanese Kaguya in 2007, Chinese Chang'e 1 in 2007, Indian Chandrayaan-1 in 2008, and US Lunar Reconnaissance Orbiter in 2009.

In-Situ Resource Utilization (ISRU) refers to any activity exploiting the extraterreatrial raw materials, mainly mineral resources. Such activity is also called space mining. It may involve chemical processing of minerals. For example, material extraction from regolith such as oxygen, volatile, metal, silicon, etc. ${ }^{6,7)}$ and production of construction materials such as sulfur concrete ${ }^{8)}$. On the other hand, the local soil or rocks can be used as it is. Such applications include site preparation, road construction and pavement; radiation, thermal, and meteoroid shielding 9,10); berm construction around landing site ${ }^{11)}$; thermal energy storage ${ }^{12)}$.

When exploring or living on the Moon, Mars, or other planets, ISRU would allow obtaining necessary resources in its vicinity rather than bringing them all the way from the Earth. Also, the raw material extracted or the fuel produced from the in-situ materials can be exported, for instance, from the Moon to Earth or to low earth orbit ${ }^{13)}$. This is when our economic sphere is extended to the Earth-Moon system.
Therefore ISRU is a key technology that enables long term exploration, expansion of space activities, and settlement in space.

Excavation and earthmoving is an essential initial step of ISRU activities. Given the limited power consumption and mass for an excavator, it is important to optimize the excavation condition. The optimal excavation condition should depend on the conditions of the ground, such as relative density. Through experimentation with lunar regolith simulants, this study shows the optimal ripping condition and its dependency on soil conditions.

\subsection{Past research on lunar regolith excavation}

There have been many research projects dealing with excavation of lunar regolith. Some people evaluated existing analytical models of excavation forces.Willman and Boles ${ }^{14)}$ concluded existing analytical models were statistically invalid in predicting their experiment results, whereas Blouin et al. ${ }^{15}$ called for a common ground for comparing models. King et al. ${ }^{16)}$ compared predicted excavation forces by 7 analytical models against the measured reaction force on a rod, not a realistic shape of dozer blade. They showed some models better fit experiment data than others. To evade such puzzling models, Nakashima et al. ${ }^{17)}$ proposed a very simple engineering parameter, called a specific cutting resistance, to characterize excavation force. Of course, numerical simulation plays an important role. Discrete Element Method (DEM) is getting attention for its capability of modeling grain shapes ${ }^{18)}$.

Excavation methods that require less excavation energy have been studied such as vibrating bulldozer blades ${ }^{19)}$, percussive and pneumatic methods ${ }^{20)}$, and ripping ${ }^{21)}$. Also robotic excavation systems have been developed such as a bucket wheel excavator ${ }^{22)}$ and a bucket ladder excavator ${ }^{23)}$.

Analytical and empirical models of excavation forces have been applied to estimate the soil density of lunar regolith based on measured excavation force ${ }^{24,25}$. 


\section{Lunar Regolith}

\subsection{Naturally occurring lunar regolith}

Lunar regolith is a layer of fragments or debris of the bedrock generated by "the continuous impact of largeand small meteoroids and the steady bombardment ofthe lunar surface by charged atomic particles from thesun and the stars." 26) According to past observations, it is known that almost entire surface of the Moon is covered by the lunar regolith. The estimated thickness of the lunar regolith layer is $4 \mathrm{~m}$ to 5 $\mathrm{m}$ in the mare areas, and $10 \mathrm{~m}$ to $15 \mathrm{~m}$ in the older highland regions ${ }^{26)}$.

\subsection{Lunar regolith simulants}

To facilitate researches, the simulants of the lunar regolith have been manufactured by several organizations. The simulants produced in Japan include FJS-1 ${ }^{27)}$ and MKS-1. FJS-1 was developed in 1990's and is still used in recent researches ${ }^{17,18)}$. JSC-1 produced in the U.S. has been widely used. When the stock of JSC-1 got short, JSC-1A was manufactured according to the same specifications as JSC-1A.

Those simulants resemble the lunar regolith in the mare regions. On the other hand, to simulate the highland regolith, the NU-LHT ${ }^{28)}$ series has been developed. Also, to use for vehicle testing, a simulant with lower fidelity, such as GRC-1 ${ }^{29)}$, is used. Other types of lunar regolith simulants include Canadian OB-1 ${ }^{30}$ ) for highland, Chinese CAS-1 ${ }^{31}$ and NAO- ${ }^{32)}$ for mare and highland.

\section{Setup and Procedure of Excavation Experiment}

The experiment setup (Fig. 1) consists of a soil box filled with simulant, an excavation tool, and a tool carriage that support and push horizontally a tool at a constant speed. The speed of pushing a tool is as slow as about $8 \mathrm{~mm} / \mathrm{s}$ so that the phenomenon of excavation is free from the effect of inertia.

The horizontal force acting on an excavation tool is measured by a load cell on the tool carriage. The soil box is an aluminum box of $900 \mathrm{~mm}$ long and $350 \mathrm{~mm}$ wide. The box is filled with soil of $100 \mathrm{~mm}$ deep, which means roughly $60 \mathrm{~kg}$ of simulant used. Excavation tools used are a ripper and a wide blade as shown in Fig. 2. Tines of a ripper are made of
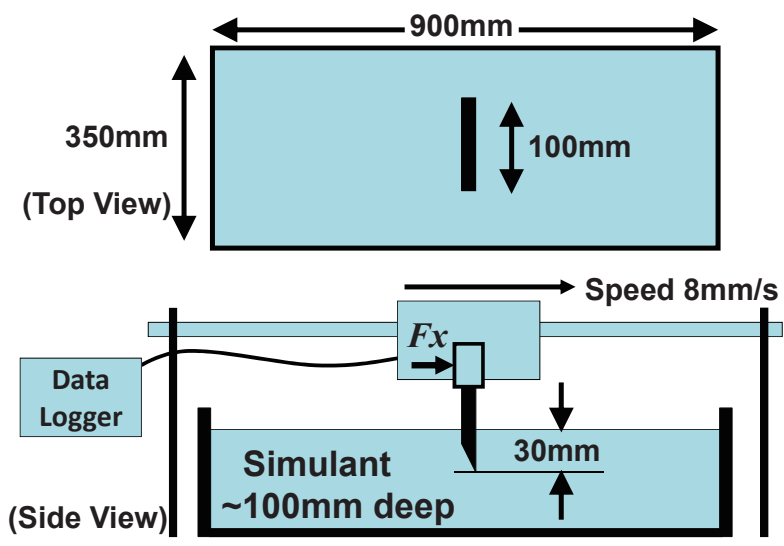

Fig. 1. Schematic of experiment setup.
$1.7 \mathrm{~mm}$ thick stainless steel. Up to eight of them can be attached to a ripper at $15 \mathrm{~mm}$ interval. The length of a tine is $75 \mathrm{~mm}$. The number and the spacing of tines on a ripper are changed for different test conditions. Each position for attaching a tine is labeled from $\# 1$ to $\# 8$ as indicated in Fig. 2.These numbers are used to identify the configuration of a ripper. A wide blade is an aluminum plate of $100 \mathrm{~mm}$ wide and $6 \mathrm{~mm}$ thick. Tines on a ripper and a wide blade are fixed vertical to the surface of the soil.

Two types of test materials were put in the soil box, namely 1) JSC-1A, and 2) construction sand. JSC-1A is a simulant developed by NASA, simulating a sample of low titanium basaltic regolith in the mare obtained in the Apollo 14 mission ${ }^{33)}$. The grain size distributions of JSC-1A and the construction sand are shown in Fig. 3. The grain shapes of JSC-1A and construction sand are classified as angular to sub-angular, androunded to sub-rounded, respectively.

The experiment procedure has three steps (Fig. 2). First, a test material is compacted by running a vibratory motor for certain duration on the simulant surface. The simulant density was set to three levels: dense, medium-dense, and loose. Each level corresponds to $1.88 \mathrm{~g} / \mathrm{cm}^{3} \quad\left(D_{\mathrm{r}}=76 \%\right), 1.81 \mathrm{~g} / \mathrm{cm}^{3}$ $\left(D_{\mathrm{r}}=61 \%\right)$, and $1.71 \mathrm{~g} / \mathrm{cm}^{3}\left(D_{\mathrm{r}}=43 \%\right)$, respectively, where $D_{\mathrm{r}}$ stands for relative density ${ }^{*}$. Second, the compacted test material is loosened by a ripper. The number and positions of tines were changed to have five different tine settings. Tine settings are identified by listing the numbers of the positions where tines are attached, such as [1 to 8], [1/3/5/7], [1/8], [3/6], and [4] in which the numbers are defined in Fig. 2. For example, [3/6] means that two tines are attached to positions $\# 3$ and \#6. This notation is used below and in Fig. 4. Third, the test material loosened in the previous step is moved or excavated by a wide blade. As a control experiment, excavation runs by a wide blade were made without prior ripping, in other words, without loosening of the second step.

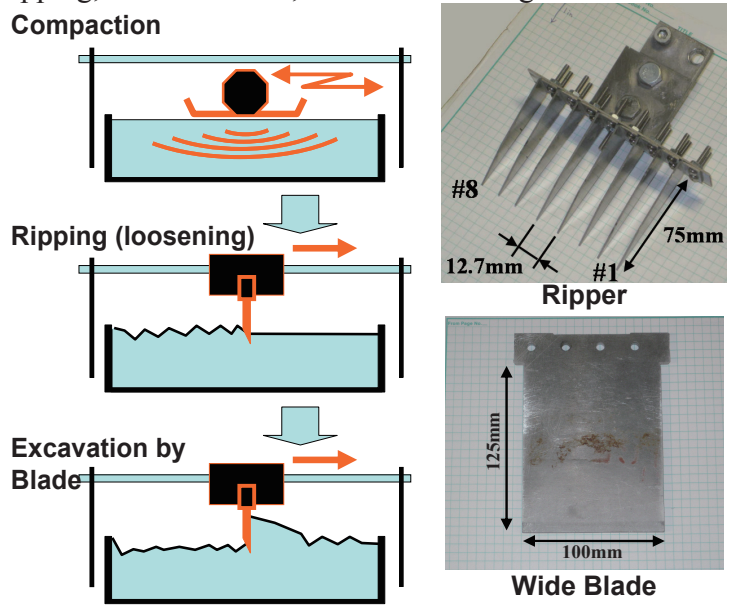

Fig. 2. Experiment procedure (left) and excavation tools (right).

\footnotetext{
* The relative density, $D_{\mathrm{r}}$, of dry soil with bulk density of $\rho$ is defined as $D_{\mathrm{r}}=\left(1 / \rho_{\min }-1 / \rho\right) /\left(1 / \rho_{\min }-1 / \rho_{\max }\right)$ where $\rho_{\min }$ and $\rho_{\max }$ are minimum and maximum dry density, according to ASTM D 4254. $D_{\mathrm{r}}$ is usually expressed as a percentage.
} 

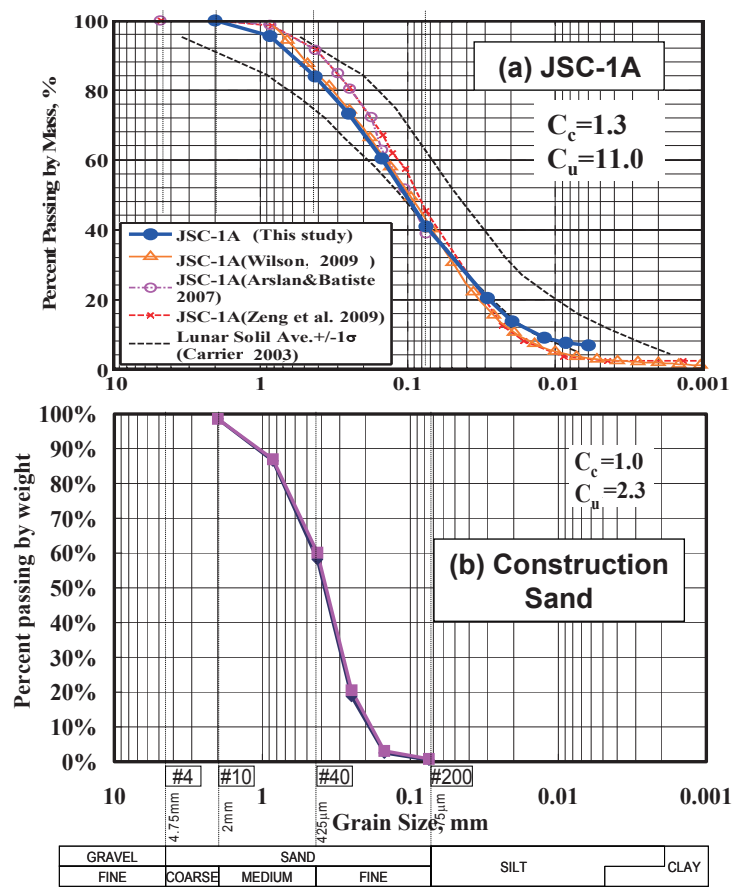

Fig. 3. Grain size distribution.(a) JSC-1 $\mathrm{A}^{34)}$, (b) construction sand.

The depth of excavation is fixed at $30 \mathrm{~mm}$ for both a ripper and a wide blade.

\section{Results and Discussion}

Results of experiments are shown in Fig. 4. Each plot corresponds to different bulk density. Each bar on a plot represents different tine setting. The light colored part of a bar means the average reaction stress measured in ripping whereas the dark colored part, that of blading. In the text below, the former is called the ripping resistance, and the latter called the blading resistance. The sum of the ripping resistance and the blading resistance is termed the total resistance.

Note that the abscissa of plots in Fig. 4 means the reaction force normalized by the area of a wide blade and averaged over the excavation distance although it appears as the energy per unit volume, or specific energy (SE) with its unit being $\mathrm{J} / \mathrm{m}^{3}$. This is because the value of specific energy is calculated as below. Specific energy is defined by

$$
S E=\frac{\int_{0}^{L} F(x) d x}{w d L}
$$

where $F(x)$ is the blading resistance or ripping resistance as a function of excavation distance, $w$ is the width of a wide blade $(=100 \mathrm{~mm}), d$ is the excavation depth $(=30 \mathrm{~mm})$, and $L$ is the total excavation distance. Note that the value of $w$ is $100 \mathrm{~mm}$ even when calculating the specific energy for ripping. Thus, the value of SE is proportional to an averaged resistance force. Fig. 4(a) to (c) shows the results of experiments with JSC-1A. Fig. 4 (d) is for the terrestrial construction sand. The bulk density for (d) was set to dense, the same as the density for (a).

\subsection{Effect of relative density}

The effect of relative density can be understood by comparing Fig. 4 (a), (b), and (c). For dense condition of (a), the total resistance peaks with a four tine ripper [1/3/5/7], which is about $20 \%$ less than that with no ripping. Medium-dense condition of (b) shows the same trend. Yet, the reduction of the total resistance is smaller than in case of (a). For loose condition of (c), the ripping resistance increases as the number of tines on a ripper increases. The blading resistance remains almost constant regardless of tine setting.

This means that ripping on already loose material has little effect. Therefore, ripping prior to blading is beneficial on dense or medium-dense material whereas it has negative effect on loose material.

\subsection{Comparison with construction sand}

The similarity between loose JSC-1A and construction sand is seen by comparing Fig. 4 (c) and (d). The case of (c) was explained in the previous subsection. Although construction sand of (d) is prepared to be dense $\left(1.79 \mathrm{~g} / \mathrm{cm}^{3}, D_{\mathrm{r}}=78 \%\right)$, ripping prior to blading did not influence the blading resistance. Thus, loose JSC-1A and dense construction sand showed similar result in a sense that ripping has little effect on blading resistance. This observation can be given the following interpretation. The weak interlocking of grains eliminates the effect of ripping. Although JSC-1A has angular to sub-angular grain shape, JSC-1A was prepared to be loose for condition of (c), which resulted in weak interlocking.

Construction sand, on the other hand, has rounded to sub-rounded grains, which has less interlocking, even though it is compacted to dense. Therefore, it can be said that the characteristics of the lunar regolith, that is angular grains and high relative density, make ripping effective.

\subsection{Scaling by gravity}

Consideration regarding the cutting depth is given below from three aspects: depth scaling due to gravity, resistance force mode, and critical depth.

Experiments were conducted in Earth's gravity of $1 \mathrm{~g}$ with the cutting depth set to be $30 \mathrm{mmwhile}$ those experiments simulate the phenomena in the lunar gravity of $1 / 6 \mathrm{~g}$.

According to the principle of similitude, the length has to be scaled 6 times larger on the Moon than on the Earthif the stress state and the density of the material, i.e. JSC-1A, are assumed to be unchanged in Earth's gravity and lunar gravity ${ }^{35)}$. Thus, the cutting depth of $30 \mathrm{~mm}$ in Earth's gravity corresponds to that of $180 \mathrm{~mm}$ in the lunar gravity.

\subsection{Effect of depth}

An analytical three dimensional cutting model suggests that the effectiveness of ripping would be reduced as the cutting depth gets deeper. The dependence of the cutting resistance on depth differs between the wide blade and the ripper. Since the ripper is much narrower than the wide blade in our experiments, the resistance force on the ripper is affected more by the effect of the side failure zones than that of the wide blade. The cutting resistance model gives some insights into the different effects of depth on the front failure zone and the side failure zone. McKyes and Ali'sanalytical model ${ }^{36)}$ of cutting resistance, $P$,is

$$
P=\left(\gamma d^{2} N_{\gamma}+c d N_{c}+q d N_{q}\right) w
$$

where is the cutting depth, $w$ is the cutting width, $\gamma$ is the unit weight of soil, and 


$$
N_{\gamma}=\frac{1}{2}\left(\frac{1}{\tan \alpha}+\frac{1}{\tan \beta}\right)\left(1+\frac{2}{3} \frac{d}{w} \sqrt{\frac{1}{\tan ^{2} \beta}+\frac{2}{\tan \alpha \tan \beta}}\right) \frac{\sin (\beta+\phi)}{\sin (\alpha+\beta+\delta+\phi)}
$$

Detailed explanation about thismodel is omitted as it is out of the scope of this paper. Note, however, that the second set of parentheses in $N_{\gamma}$ hastwo terms: 1 and a term that contains $d / w$.

The former term corresponds to the front failure zone whereas the latter to the side failure zone. Thus the resistance, $P$, due to the front failure zone is proportional to the square of the cutting depth, $d^{2}$, while the effect of the side failure zone is proportional to the third power of the cutting depth, $d^{3}$.Similar arguments apply to the terms of $N_{c}$ and $N_{q}$. Therefore the ripping resistance increases more rapidly as the depth increases than the blading resistance. This should result in the reduced effectiveness of ripping at the larger cutting depth.

In addition, it is known that there exists the critical depth, $d_{\mathrm{c}}$, below which the soil pushed by a blade does not move upward $^{37)}$. In other words, the part of a ripper tine below the depth of $d_{\mathrm{c}}$ does not loosen the soil as effectively as the part above $d_{\mathrm{c}}$. The depth of cutting should be around or shallower than $d_{\mathrm{c}}$ to achieve optimal effectiveness.

The above considerations suggest that the effectiveness of ripping prior to blading degrades as the cutting depth increases.

On the other hand, it is obvious that loosening by the ripper is ineffective if the depth of ripping is too shallow in relation to the spacing of ripping tines. Therefore the optimal depth of cutting needs to be investigated through experiments, which is among the future work.

\section{Conclusion}

It was shown through experiments that the characteristics of the lunar regolith, i.e. angular grains and high relative density, made ripping effective in improving excavation efficiency. By using a ripper, the total resistance was reduced by $20 \%$ at maximum under a condition of relative density greater than $60 \%$. The optimal tine spacing of a ripper is $15 \mathrm{~mm}$ for the excavation depth of $30 \mathrm{~mm}$ in the lab, which corresponds to $180 \mathrm{~mm}$ in the lunar gravity. Contrary, ripping won't work on loose simulant as well as dense construction sand because of lesser interlocking between grains. Additionally, by theoretical consideration, negative effects of both too deep and too shallow excavation are identified, which suggest that there exits an optimal excavation depth. More technical details have been discussed in elsewhere ${ }^{35}$.

\section{References}

1) Gertsch, R. E.: A Method for Mining Lunar Soil,Space Manufacturing 1983, Proc. the Sixth Princeton Conference on Space Manufacturing, Advances in the Astronautical Sciences, American Astronautical Society, AAS 83-234, San Diego, CA, 53 (1983).

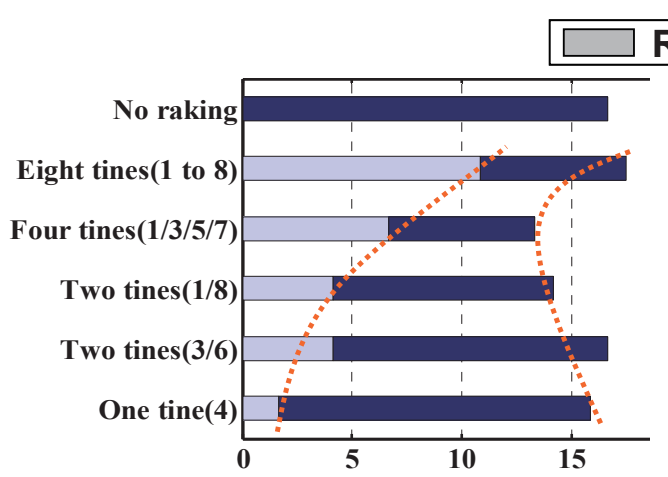

(a) Dense $1.88 \mathrm{~g} / \mathrm{cm}^{3}$

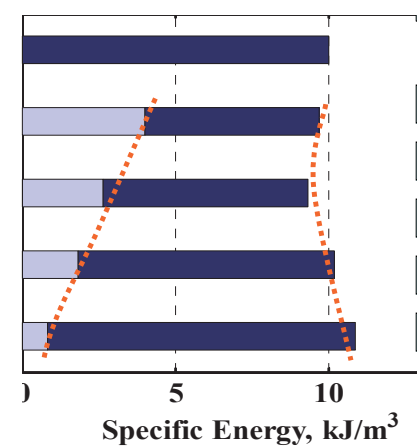

(b) Medium $1.81 \mathrm{~g} / \mathrm{cm}^{3}$

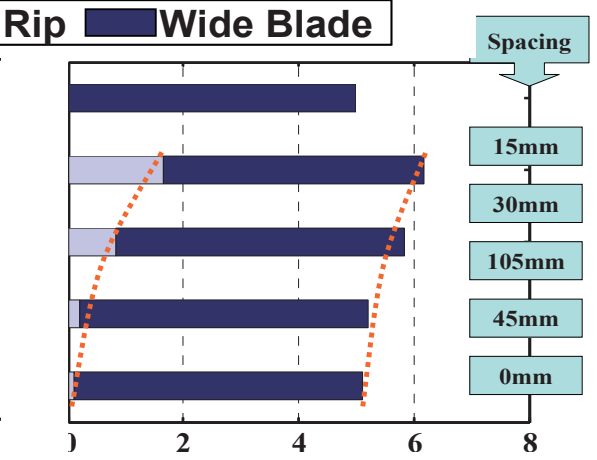

(c) Loose $1.71 \mathrm{~g} / \mathrm{cm}^{3}$

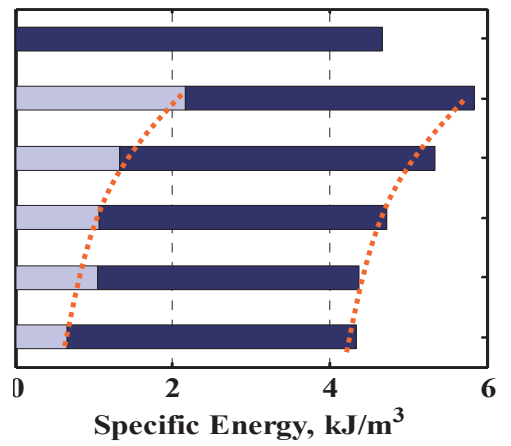

(d) Terrestrial Sand

Fig. 4. Excavation energy. (a) through (c) are data for different density of JSC-1A; (d) is data for terrestrial sand. 
2) Ishikawa, N., Kanamori, H. and Okada, T.:The Possibility ofConcrete Production on the Moon, Proceedings of The Second Conference on Lunar Bases and Space Activities of the 21st Century, Johnson Space Center, Houston, TX, (1992), pp. 489-491.

3) Allen, C. C., Bond, G. G. and McKay, D. S.: Lunar Oxygen Production - A Maturing Technology, Engineering, Construction, and Operations in Space IV, American Society of Civil Engineers, (1994), pp. 1157-1166.

4) Freundlich, A., Ignatiev, A., Horton, C., Duke, M., Curreri, P., Sibille, L.: Manufacture Of Solar Cells On The Moon,Photovoltaic Specialists Conference, 2005, Conference Record of the Thirty-first IEEE, (2005), pp. 794- 797.

5) Aoki, Shigeru: Lunar Solar Power Generation,"The LUNA RING",Concept and Technology, JUSTSAP 2009.

6) Nakamura, T., and Senior, C. L.: Solar Thermal Power for Lunar Materials Processing, J. Aerosp. Engrg.,21(2), (2008), pp. 91-101.

7) Nayagam, V., and Sacksteder, K. R.: A Vibrofluidized Reactor for Resource Extraction from Lunar Regolith, STAIF 2006, AIP Conf. Proc., 813, (2006), pp. 1101-1110, doi:10.1063/1.2169291.

8) Meyers, C., and Toutanji, H.: Analysis of Lunar-Habitat Structure Using Waterless Concrete and Tension Glass Fibers, J. Aerosp. Engrg.,20(4), (2007), pp.220-226.

9) Lindsey, N. J.: Lunar Station Protection: Lunar Regolith Shielding,Proceedings of the International Lunar Conference 2003, Session 5: Science of, from, and on the Moon: Life Sciences and Habitation, Hawaii Island, Hawaii, (2003).

10) Schonberg, W. P., Schäfer, F., and Putzar, R.: Some Comments on the Protection of Lunar Habitats against Damage from Meteoroid Impacts, Journal of Aerospace Engineering, 23 (1), (2010), pp. 90-97.

11) Skonieczny, K., Huber, S., Wettergreen, D. and Whittaker, W.: Identifying Key Design Parameters for Robotic Lunar Construction and ISRU, Paper 4.1, PTMSS 2009, 7-10 June, Toronto, ON, (2009).

12) Balasubramaniam, R., Wegeng, R.S., Gokoglu, S.A., Suzuki, N.H. and Sacksteder, K.R.: Analysis of Solar-Heated Thermal Wadis to Support Extended-Duration Lunar Exploration, NASA Technical Memorandum, AIAA-2009-1339, NASA/TM-2010-216254, (2010).

13) Jones, E. M.: A quasi-economic role for lunar science, LA-UR-89-3288, 40th congress of the International Astronautical Federation, Malaga, Spain, 7-13 October, (1989).

14) Willman, B. M., and Boles, W. W.:Soil-Tool Interaction Theories as They Apply to Lunar Soil Simulant, Journal of Aerospace Engineering, 8(2), (1995), pp. 88-99.

15) Blouin, S., Hemami, A., and Lipsett, M.: Review of resistive force models for earthmoving processes, J. Aerosp. Engrg.,14(3), (2001), pp. 102-111.

16) King, R.H., van Susante, P.J., Gefreh, M.A.: Comparing Blade/Soil Interaction Models in a MATLAB Program to Measurements Of Forces to Push Narrow Rods through Sand and Simulant Materials for Design of Extraterrestrial Soil Handling Machines, Space Resources Roundtable XI/Planetary \& Terrestrial Mining Sciences Symposium, Golden, Colorado, (2010).

17) Nakashima, H., Shioji, Y., Tateyama, K., Aoki, S., Kanamori, H., And Yokoyama, T.: Specific Cutting Resistance of Lunar Regolith Simulant under Low Gravity Conditions, Journal of Space Engineering, 1(1), (2008), pp.58-68.

18) Matsushima, T., Katagiri, J., Uesugi, K., Tsuchiyama, A., and Nakano, T.: 3D Shape Characterization and Image-Based DEM Simulation of the Lunar Soil Simulant FJS-1, J. Aerosp. Engrg.,22(1), (2009), pp. 15-23.

19) Szabo B., Barnes F., Sture S., Ko H.-Y.: Effectiveness of vibrating bulldozer and plow blades on draft force reduction, Transactions of the ASAE, 41(2), (1998), pp. 283-290.
20) Zacny, K., Mueller, R., Galloway, G., Craft, J., Hedlund, M., Mungas, G. and Wilson, J.: Percussive And Pneumatic Approaches To Lunar Excavation And Mining, Proc. Planetary and Terrestrial Mining Science Symposium, Paper 3-1, NORCAT, Ontario, Canada, (2009).

21) Iai, M. and Gertsch, L.: Effect of Regolith Compaction on Ripping Efficiency, AIAA 2010-1549, 48th AIAA Aerospace Sciences Meeting Including the New Horizons Forum and Aerospace Exposition, Orlando, Florida, (2010).

22) Johnson, L.L., and King, R.H.: Measurement of force to excavate extraterrestrial regolith with a small bucket-wheel device, Journal of Terramechanics, (2009).

23) Iai, M.: Lunar Miner: a regolith excavator competed in NASA centennial challenge, Proc. Planetary and Terrestrial Mining Science Symposium, Paper 6-5, NORCAT, Ontario, Canada, (2007).

24) Kobayashi, T., Ochiai, H., Fukagawa, R., Aoki, S., and Tamoi, K.: A Proposal for Estimating Strength Parameters of Lunar surface from Soil Cutting Resistances, ASCE Earth and Space 2006.

25) Iai, $M$ and Gertsch, L.: Soil Density from Ripping Force Measurement during Site Preparation, ASCE Earth \& Space 2010, 12th Biennial International Conference On Engineering, Science, Construction And Operations In Challenging Environments, Honolulu, Hawaii, March 17, (2010), doi:10.1061/41096(366)24.

26) McKay, D. S., Heiken, G., Basu, A., Blanford, G., Simon, S., Reedy, R., French, B. M., and Papike, J.: The Lunar Regolith, Lunar Sourcebook, Ch. 7, Heiken, G. H., Vaniman, D. T., and French, B. M., eds., Cambridge Univerisity Press, Cambridge, UK, (1991), pp.285-356.

27) Kanamori, H., Udagawa, S., Yoshida, T., Matsumoto, S., and Takagi, K.: Properties of Lunar Soil Simulant Manufactured in Japan, ASCE Space 98, Proc. the Sixth International Conference and Exposition on Engineering, Construction, and Operations in Space, April 26-30,Albuquerque, New Mexico,(1998), pp. 462-468.

28) Zeng, X., He, C., and Wilkinson, A.: Geotechnical Properties of NT-LHT-2M Lunar Highland Simulant, J. Aerosp. Engrg.23(4), (2010), pp.213-218.

29) Oravec, H.: Understanding mechanical behavior of lunar soils for the study of vehical mobility, PhD dissertation, Case Western Reserve University, Cleveland, Ohio (2009).

30) Richard, J., Sigurdsonand, L. and Battler, M. M.: OB-1 lunar highlands physical simulant evolution and production, 2007 Lunar and Dust Regolith Simulant Workshop, (2007).

31) Zheng, Y., Wang, S., Li, C., Ouyang, Z., Feng, J., Liu, J. and Zou, Y.: The Development of CAS-1 Lunar Soil Simulant, International Lunar Conference 2005.

32) Li, Y., Liu, J., and Yue, Z.:NAO-1: Lunar Highland Soil Simulant Developed in China,J. Aerosp. Engrg.22, (2009), pp.53-57.

33) Sibille, L., Carpenter, P., Schlagheck, R., and French, R. A.: Lunar Regolith Simulant Materials: Recommendations for Standardization, Production and Usage, Marshall Space Flight Center, Huntsville, Alabama, (2005).

34) Iai, M. and Luna, R.: Direct Shear Tests on JSC-1A Lunar Soil Simulant, Journal of Aerospace Engineering, (2011), pp.433-441, $<\mathrm{http} / /$ dx.doi.org/10.1061/(ASCE)AS.1943-5525.0000082>

35) Iai, M.: Scaled Experimental Study on Excavation of Lunar Regolith with Rakes/Rippers and Flat Blade, PhD dissertation, Missouri University of Science and Technology, 2010.< http://scholarsmine.mst.edu/thesis/Scaled_experimental__09007dcc8 0849963.html>

36) McKyes, E. and Ali, O.S.: The cutting of soil by narrow blades, Journal of Terramechanics, 14(2), (1977), pp.43-58.

37) McKyes, E.: Agricultural Engineering Soil Mechanics, Developments in Agricultural Engineering 10, Elsevier, (1989), pp.207-208. 